\title{
Evaluation of TLR4 expression and chosen parameters of oxidative-antioxidative balance in young children with food allergy
}

\author{
Barbara Kamer ${ }^{1}$, Karolina Kulig ${ }^{1}$, Przemysław Lewkowicz ${ }^{2}$, \\ Anna Kamer-Bartosińska ${ }^{3}$, Henryk Tchórzewski ${ }^{2}$
}

${ }^{1}$ Second Department of Pediatrics and Allergology, ${ }^{2}$ Department of Clinical Immunology,

${ }^{3}$ Surgical Gynecology Department, Polish Mother's Memorial Hospital - Research Institute, Łódź, Poland

\begin{abstract}
The authors evaluated mRNA TLR4 expression on neutrophils and the chosen parameters of oxidative-antioxidative balance in blood of 35 children with food allergy (17 of them with IgE-dependent allergy and 18 with IgE-independent allergy) and 15 healthy children without any allergy. The age of these children ranged from 1 to 36 months. Children with food allergy in comparison with healthy children were found to have lower mRNA TLR4 expression, higher average value of chemiluminescence (CL) and its increase after stimulation by fMLP, PMA and OZ as well as lower TAS values. Disturbances of oxidative-antioxidative balance were found in children with food allergy. We suggest that natural immunity is involved in the development of food allergy mechanisms. Moreover, chemiluminescence can be used as an additional diagnostic test.
\end{abstract}

Key words: allergy, young children, TLR4 receptor, chemiluminescence, TAS, oxidative-antioxidative balance.

\section{Introduction}

Food allergy is an important and rising clinical problem [1-3]. The pathogenesis of allergic diseases is not yet clear. In persons allergic to foods after eating harmful food, there appear some mastocytes releasing histamine and tryptase, as well as eosinophils and neutrophils [4]. Eosinophils are important cells contributing to the development of allergic reaction as well as participating in maintaining the general and local inflammatory reaction [5-7]. There are also several TLRs receptors expressed on their surfaces [8]. Neutrophils on the other hand play an important role in delayed allergic reactions $[9,10]$ as well as in natural immunity, inflammation and immunoregulation. Neutrophils secrete cytokines (IL-13, IL-6, IL-8, IL-12). Several TLR receptors which are transmembrane proteins are present on the neutrophils' surface. Among them are TLR 1, 2, 4, 5 and 6 , which have both intra-

Correspondence: B. Kamer, Second Department of Pediatrics and Allergology, Polish Mother's Memorial Hospital -

Research Institute, 281/289 Rzgowska Street, Lodz 93-338,

Poland; tel.: (+4842) 2712091, fax.: (+4842) 2711386,

e-mail: bkamer@wp.pl cellular and surface expression, whereas the expression of TLR receptors 7, 8, 9 is mainly intracellular, where they identify virus or bacterial nucleic acids [11-13]. Many authors suggest an essential contribution of TLR4 (component of natural immunity) in the development of allergic reactions. A stimulation of TLR4 receptor e.g. allergens leads to the activation of nuclear factor kappa B (NF-kB) and many genes included in the immunologic reaction [14-16]. TLR4 receptor also influences the functions of neutrophils [17]. The connections between TLR4 receptor, neutrophils and food allergy have not been explained fully yet. Recently, besides the well known pathogenic mechanisms contributing to allergic reaction, an important role of reactive oxygen species (ROS) is underlined too, among them are: superoxide anion, hydroxyl radical, singlet oxygen and peroxyl radical. The release of these compounds from neutrophils is accompanied by photon emission measured by chemiluminescence (CL) $[18,19]$. ROS created in the cell have influence on different structures and, can also activate NF- $\mathrm{KB}$ and numerous genes. ROS excess is neutralized by antioxidative system [20-22]. Physiologically, the balance between oxidative and antioxidative processes in the body is maintained. Disorders 
in this balance can lead to oxidative stress which results in more and more frequent reactions with ROS presence. The results of the research of other authors, including our previous studies in children with food allergy showed an increase of CL [19,21,23]. Besides, many authors have also shown an increase of chemiluminescence in children with bronchial asthma [24-27] and weakening of this phenomenon in children with recurrent respiratory infections $[23,28,29]$. The aim of this study was the estimation of mRNA TLR4 receptor expression on the surface of neutrophils and on the chosen parameters of oxidative-antioxidative system in the blood of young children with food allergy.

\section{Material and methods}

Patients. 35 children suffering from food allergy and 15 healthy children hospitalized in the Second Department of Pediatrics and Allergology at the Polish Mother's Memorial Hospital- Research Institute were included in this study. The age of these children ranged from 1 to 36 months. Among the examined children infants were most numerous constituting $58 \%$ of patients. The basis of the diagnosis of cow's milk proteins allergy was the presence of allergy symptoms, positive results of elimination and the provocation challenge on cow's milk proteins. Moreover, it was also shown through the presence of antigen-specific IgE antibodies (asIgE) against milk proteins marked in blood sera. Among them 17 children had asIgE against cow's milk proteins $\geq 2$ class according to 4 degrees classification of atopy, and were included in IgE-dependent allergy group. The remaining 18 children with correct results of asIgE against milk proteins were included in $\operatorname{IgE}$-independent allergy group. The children from the control group had normal somatic development, were healthy and had no symptoms of infectious disease for at least the past 4 weeks.

Total allergen-specific IgE (asIgE). Total allergen-specific IgE against milk proteins which was performed in blood sera with immunochemical method using IgE FAST PLUS test kit 3M 'Diagnostic System". Concentration $\geq 2$ class $(\geq 0.76 \mathrm{IU} / \mathrm{ml})$ was considered abnormal according to four degree classification of atopy [30].

TLR 4 expression assay. Whole blood granulocytes isolated in mean amount $10^{6}( \pm 4 \%)$ were resuspended in $30 \mu \mathrm{l}$ of PBS and total RNA isolation was carried out using RNeasy Mini Kit (Qiagen,USA) according to manufacturer's procedure. A single -stage reaction was carried out with the help of Techne Flexi Gene (GB) thermocycler and One-step RT-PCR Kit (Qiagen, USA) using $10 \mu \mathrm{l}$ of total RNA isolated were used to amplification TLR 4 specific product. Thermal profile of RT-PCR reaction were as follows: 30 cycles $-52^{\circ} \mathrm{C}-30 \mathrm{~min} ., 95^{\circ} \mathrm{C}-15 \mathrm{~min} ., 94^{\circ} \mathrm{C}-35 \mathrm{sec} ., 49^{\circ} \mathrm{C}-$ $45 \mathrm{sec}$., $72^{\circ} \mathrm{C}-1 \mathrm{~min}$. RT-PCR reaction product analysis was carried out using agarose electrophoresis (1.7\% gel, TAE buffer) followed by ethidium bromide staining and EDAS 290 (Kodak, USA) scanning system with Kodak 1D Image Analysis Software. To evaluate TLR 4 expression rate " 0 " to "10" optical density (OD) was adopted, where "0" was the lowest OD and "10" the highest one. The values between this range show relative expression of TLR receptor.

Neutrophils chemiluminescence (CL). The activity of human neutrophils in the resting state and after priming with TNF (10 $\mathrm{ng} / \mathrm{ml}$ ) was assessed. The tests were prepared using the whole blood CL method with luminol and the following patterns were applied: no stimulators and after stimulation with bacterial peptide $\mathrm{N}$-formyl-methionyl-leucyl-phenylalanine (fMLP), opsonised zymosane $(\mathrm{OZ})$ and phorbol myristate acetate (PMA). In the priming pattern, the blood samples were incubated for $15 \mathrm{~min}$ at $37^{\circ} \mathrm{C}$ with TNF $\alpha(10 \mathrm{ng} / \mathrm{ml})$ before performing the measurements. CL measurements were performed at $37^{\circ} \mathrm{C}$ with a MLX Microtiter Plate Luminometer (Dynex, USA). The CL intensity was measured for $0.2 \mathrm{sec}$. every $2 \mathrm{~min}$ and expressed in Relative Light Units (RLU) Max and Total.

Total antioxidant status (TAS). Antioxidants were measured in the sera. All reagents were provided by Randox Lab (UK). The examination was performed using a Randox Lab. set on 96-cell transparent plates. The reading the absorbance of the examined serum samples and standards was performed with the help of a method of one-point measurement with wavelengths of 550 and $630 \mathrm{~nm}$. The method is based on the ability of antioxidants to reduce the radical action of ABTS + (catio 2,2'-azino-bis[3-ethylobenzothazolino- 6 sulfonate]) and to cause suppression of color production in the sample. The obtained blue-green was measured at $600 \mathrm{~nm}$. The initial absorbance (after adding chromogen) and absorbance $3 \mathrm{~min}$ after adding the substrate (hydrogen peroxide) were measured. The concentration of antioxidant was calculated based on the absorbance after adding the substrate and the initial absorbance. The results were shown in $\mathrm{mmol} / \mathrm{l}$.

Ethical issues. The research was approved by the Polish Mother's Memorial Hospital Ethical Committee and each time the consent of parents or guardians was given.

Statistical analysis. For parameters expressed by a range scale (continuous parameters), the mean and standard deviation (SD) were calculated. Normal distribution was confirmed with the help of Shapiro-Wilk test at significance level $p=0.05$. The means were compared between the groups by t-Student test for independent samples, and if the distribution normality hypothesis was rejected, nonparametric Mann-Whitney U test was used. The frequency of the given features occurrence when compared between the groups was evaluated with the help of $\chi^{2}$ (chi-square) test, and when the assumptions were not fulfilled a more accurate Fisher's test was used.

\section{Results}

The evaluation of mRNA TLR4 expression on peripheral blood neutrophils of all children with allergy and children with no allergy symptoms were shown in Fig. 1 . The results of this research revealed that the average expression of this receptor was significantly lower in children with allergy. However, the analysis of the behavior of TLR4 receptor depending on the type of food allergy showed lower average values of this receptor in children with IgE-independent allergy $(3.42 \pm 3.45)$ than in children with IgE-dependent (4.2 \pm 2.7$)$. The obtained differences were not statistically significant ( $\mathrm{p}>0.05)$.

The average values of reactive oxygen species (ROS) in respective groups were summarized in Table 1. The average values of CL without stimulation in children with allergy and control group were similar. Only the use of factors stimulating neutrophiles such as fMLP (N-formyl- methionyl-leucyl-phenylalanine), OZ (opsonized zymosan) and PMA (phorbol myristate acetate) resulted in the intensification of the phenome- 


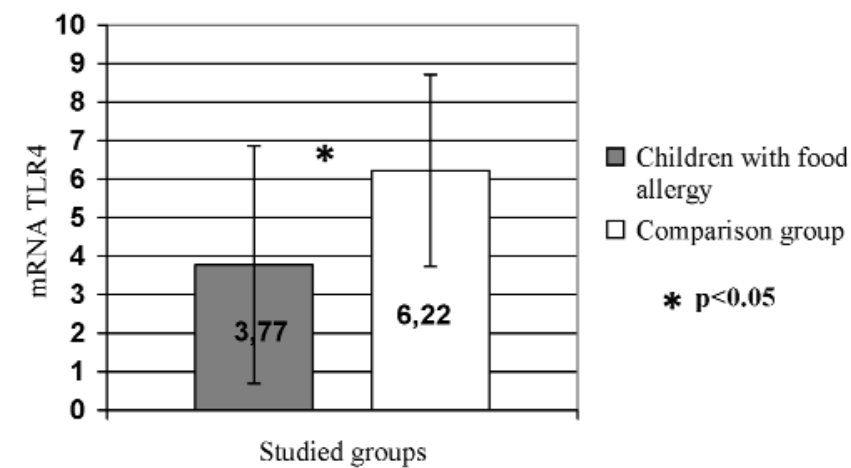

Fig. 1. Average values of mRNA TLR4 expression in investigated children. The results showed significantly lower mRNA TLR4 expression in all children with food allergy compared with reference group.

non and the significant increase in mean values of chemiluminescence in both groups of children with allergies (IgE-dependent or IgE -independent), compared with the children from the control group. The differences were more clearly marked in children with IgE-dependent food allergy, especially after stimulation by PMA and OZ. The result of the total antioxidants status (TAS) evaluation in all groups of children were shown in Fig. 2. It was found out that the TAS values in children with allergy were indeed lower compared to the examined children in the control group. At the same time the differences in the TAS values, depending on the kind of allergy and compared to the children in the control group were statistically essential only in children with IgE-dependent allergy (Fig. 3).

\section{Discussion}

Recently much research based on the mechanisms of the development of allergic inflammation has been carried out. Many authors indicate the important role of TLR4 receptor belonging to natural immunity [1113]. TLR4 is the main receptor recognizing lipopolischaride (LPS), expressed on many cells and tissues, including monocytes, macrophages and limphocytes [31-33] .The results of our research showed a lower mRNA TLR4 expression in children with food allergy both IgE-dependent and IgE-independent, compared with the reference group. It is important to stress that no data were found in medical literature concerning the estimation of this receptor in children with food allergy. However, Prescott et al. [34] and Vanhisbergh et al. [16] showed a lower expression of this receptor in children with allergy in general. The research of Remer et al. [35], important in food allergy, showed that TLR4 is directly included in respiratory burst. Lewkowicz et al. [17] indicate the role of this receptor in the modulation of the function of neutrophils. The results obtained by us suggest TLR4 contribution in

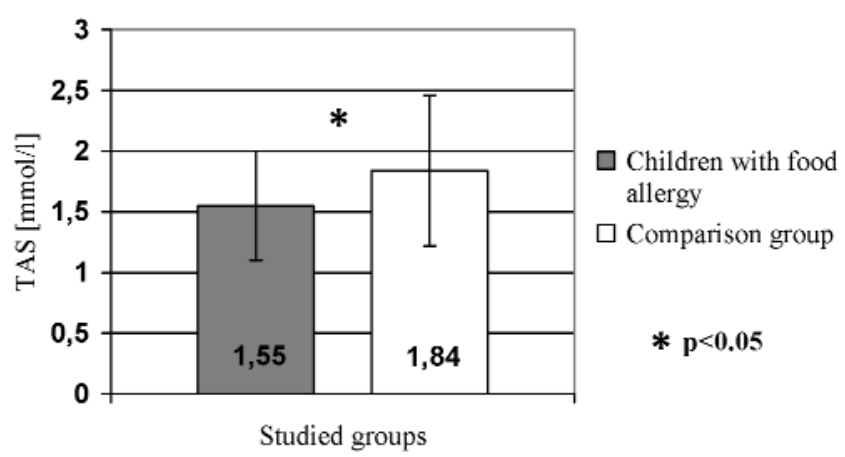

Fig. 2. Average values of TAS in investigated children. Statistical significant lower average value was present in all allergic children compared with reference group.

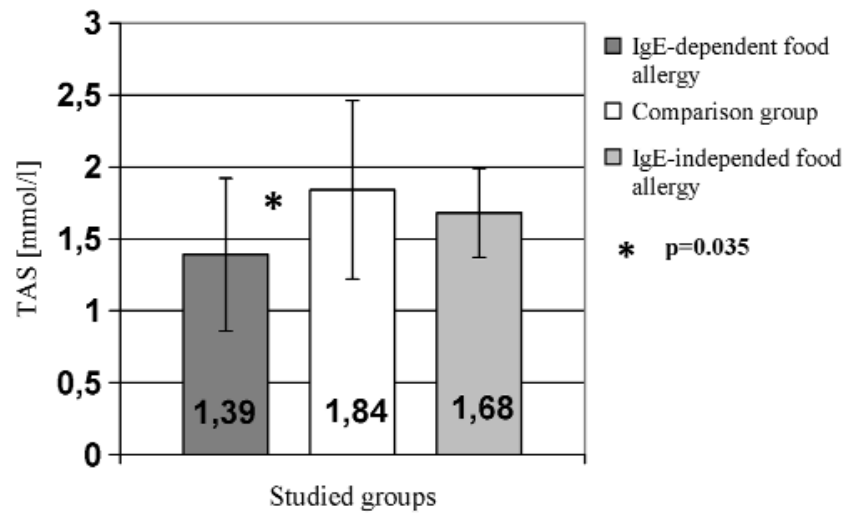

Fig. 3. Average TAS values in studied children including type of allergy. The results revealed lower TAS average values in both allergic group than in comparison group. Statistical significance was present in relation to children from IgE-dependent allergy compared with children from reference group.

the development of allergic reactions and are similar to the results of the other researchers showed TLR4 receptor presence in the pathogenesis of allergy $[25,36]$. Neutrophils are activated after being triggered by various stimulants such as: lipopolisacharydes, endotoxins, cytokines, or mediators of inflammation, which increase their metabolism and oxygen consumption. As a result of this triggering, there follows a production of highly reactive forms of oxygen (ROS) $[27,37,38]$. The analysis of the results of neutrophils activation on the basis of ROS production measured by chemiluminescence (CL), did not show differences in the primary $\mathrm{CL}$ values among the children from the analyzed groups. However, the stimulation (fMLP, PMA, OZ) leads to severity and significant increase of average values of chemiluminescence in children with food allergy, especially in IgE-dependent allergy compared with the control group. These observations are similar to the results of the previously conducted studies which showed higher mean values of CL in children with food allergies [19]. Similar observations in 
Table. 1. Analysis of average neutrophils chemiluminescence in peripheral blood of studied children including type of investigated group

\begin{tabular}{|c|c|c|c|c|c|}
\hline \multirow{3}{*}{ Chemiluminescence } & \multicolumn{5}{|c|}{ Studied group } \\
\hline & IgF-dependent & \multirow{2}{*}{$\mathrm{p}$} & Comparison & \multirow{2}{*}{$\mathrm{p}$} & $\mathrm{IgF}$-independent \\
\hline & $X \pm S D$ & & $\mathrm{X} \pm \mathrm{SD}$ & & $X \pm S D$ \\
\hline Bs max. & $0.073 \pm 0.043$ & 0.2471 & $0.057 \pm 0.032$ & 0.0608 & $0.083 \pm 0.029$ \\
\hline IMLP max. & $0.173 \pm 0.124$ & 0.0031 & $0.067 \pm 0.032$ & 0.0011 & $0.155 \pm 0.090$ \\
\hline$O \angle \max$. & $0.488 \pm 0.500$ & 0.0141 & $0.150 \pm 0.036$ & 0.0458 & $0.265 \pm 0.211$ \\
\hline PM $\wedge$ max. & $0.375 \pm 0.486$ & 0.0486 & $0.130 \pm 0.062$ & 0.0227 & $0.240 \pm 0.168$ \\
\hline Bs total. & $1.775 \pm 1.300$ & 0.5190 & $1.500 \pm 1.000$ & 0.0578 & $0.975 \pm 0.532$ \\
\hline tMI.P total & $4.975 \pm 4.777$ & 0.0470 & $2.500 \pm 1.212$ & 0.8169 & $2.575 \pm 0.574$ \\
\hline$O^{\prime} \angle$ total & $16.100 \pm 15.707$ & 0.0101 & $4.933 \pm 0.802$ & 0.0295 & $8.425 \pm 5.886$ \\
\hline PM $\wedge$ total & $17.675 \pm 15.215$ & 0.0012 & $3.567 \pm 1.206$ & 0.0003 & $7.300 \pm 3.373$ \\
\hline
\end{tabular}

CL max. - chemilumunescence max., CL total - chemiluminescence total, $\mathrm{p}<0.05$

children with bronchial asthma can be found in the results of Bush and Calhoun [39] and other authors $[21,24,27]$.These observations suggest that the activation of neutrophils in children with allergy is probably the result of the release of mediators. The free radicals (ROS) may influence the course of allergic inflammation stimulating the release of histamine by mastocytes [40] and transport of ions in the cell as well as the synthesis of prostaglandins and leukotrienes [41]. ROS have also an impact on NFKB activation [42] and thus may affect the expression of genes [35]. They can also trigger a synthesis of proinflammatory cytokines and can be intracellular apoptosis mediators [43]. Physiologically, the active forms of oxygen formed in the free radical reaction participate in oxidative reactions $[29,38,44]$, and the excess of free radicals and the products of their disintegration are neutralized by the defense mechanisms [21,44]. Normally, the balance between oxidative and antioxidative processes in the body is maintained. Disorders in this balance lead to the increase of reactions induced by the ROS, to socalled oxidative stress. The antioxidative barrier consists of enzymatic and non enzymatic components. Many authors pay attention to the impaired antioxidative barrier in children with bronchial asthma [44,45] and food allergy [21]. The results of our research in children with allergy (IgE-dependent and IgE-independent) showed a certain weakening of antioxidative barrier expressed by lower average values of antioxidative total serum capacity (TAS), in comparison with healthy children. It is also difficult to explain if the observed lower values of TAS are primary or secondary as a symptom of adaptation to raised ROS levels. However, the observed increase of ROS concentrations in the examined children may suggest that this phenomenon could also have influence on the weakening of oxidative barrier. It should be noted that the results of our study suggest a potential participation of free radical reactions in the pathogenesis of food allergy.

\section{Conclusions}

1. The authors' results may suggest involvement of natural immunity represented by the evaluation of TLR 4 expression on neutrophils in the pathomechanism of food allergy in the examined children.

2. It seems that ROS estimation by chemiluminescence may be used as an additional diagnostic test in children with allergy.

3. The examined children with food allergy present disturbances in oxidative-antioxidative balance.

Acknowledgements: This work was supported by grant no. 2 P05E 03126 of State Committee for Scientific Research of Poland.

\section{References}

[1] Evans R. Epidemiology of asthma in childhood. Pediatrician. 1991;18:250-256.

[2] Lack G. Epidemiologic risk for food allergy. J Allergy Clin Immunol. 2008;121:1331-1336.

[3] Sicherer SH, Sampson HA. Food Allergy. J Allergy Clin Immunol. 2006;117:470-475.

[4] Sampson HA. Immunologically mediated food allergy: the importance of food challenge procedures. Ann Allergy. 1988; 60:262-269.

[5] Bousquet J, Vignola AM, Campbell AM, Michael FB. Pathophysiology of allergic rhinitis. Int Arch Allergy Imunol. 1996; 110:207-218.

[ 6] Borres MP, Odelram H, Irander K, Kjellman M, Bjorgsten B. Peripherial blood eosinophilia in infants at 3 months of age is associated with subsequent development of atopic disease in early childchood. J Allergy Clin Immunol. 1995;95:694-698.

[7] Desreumaux P, Capron M. Eosinophils in allergic reaction. Curr Opin Immunol. 1996;8:790-795. 
[ 8] Rothenberg ME. Eosinophils in the new millennium. $J$ Allergy Clin Immunol. 2007;119:1321-1322.

[9] Nourshargh S. Mechanism of neuthropils and eosinophils accumulation in vivo. Am Rev Respir Dis. 1993;148:60-64.

[10] Detmers PA, Zhou D, Polizzi E, et al. Role of stress-activated mitogen-activated protein kinase (p38) in 2-integrin-dependent neutrophil adhesion and the adhesion-dependent oxidative burst. I Immunol. 1998;161:1921-1929.

[11] Bauer S, Hangel D, Yu P. Immunobiology of toll-like receptors in allergic disease. Immunobiol. 2007;212:521-533.

[12] Hayashi F, Means TK, Luster AD. Toll-like receptors stimulate human neutrophil function. Blood. 2003;102:2660-2669.

[13] Kawai T, Shizuo A. TLR signaling. Semmin Immunol. 2007; 19:24-32.

[14] Eisenbarth SC, Piggott DA, Huleatt JW, Visintin I, Herrick, CA, Bottomly K. Lipopolysaccharide-enhanced, Toll-like Receptor 4-dependent $\mathrm{T}$ helper cell type 2 responses to inhaled antigen. J Exp Med. 2002;12:1645-1651.

[15] Kaisho T, Hoshino K, Iwabe T. Endotoxin can induce MyD88-deficient dendritic cells to support Th2 cell differentiation. Int Immunol. 2002;7:695-700.

[16] Vanhinsbergh L, Powe DG, Jones NS. Reduction of TLR2 gene expression in allergic and nonallergic rhinitis. Ann Allergy Asthma Immunol. 2007;99:509-516.

[17] Lewkowicz P, Lewkowicz N, Sasiak A, Tchórzewski H. Lipopolysaccharide-activated CD4+CD25+ T regulatory cells inhibit neutrophil function and promote their apoptosis and death. J Immunol. 2006;177:7155-7163.

[18] Kantorski J, Tchórzewski H. The effect of serine and thiol protease inhibitors on chemiluminescence of human neutrophils in investigation in vitro. $J$ Biolumin Chemilumin. 1992;7:37-45.

[19] Kamer B, Zeman K, Kamer-Bartosińska A, Tchórzewski H, Lukamowicz J. Chemiluminescence of peripheral blood neutrophils in infants and small children with food allergy. Med Wieku Rozw. 2003;7:35-41.

[20] Macdonald TT. Evidence for cell -mediated hypersensitivity as an important pathogenetic mechanism in food intolerance. Clin Exp Allergy. 1995;25:10-13.

[21] Krauss H, Ignyś I, Malewski W. Indexes of oxidative stress in children with food allergy. Ped Pol. 1999;74:125-133.

[22] Martins PS, Brunialti MK, Martos LS, et al. Expression of cell surface receptors and oxidative metabolism modulation in the clinical continuum of sepsis. Crit Care. 2008;12(1): R25.

[23] Kamer B, Zeman K, Kamer-Kejna A, et al . Evaluation of certain immunological parameters in infants and small children with recurrent respiratory tract infections. Int Rev Allergol Clin Immunol. 1998;4:150-154.

[24] Jarjour NN, Cahoun WJ . Enhanced production of oxygen radicals in astma. J Lab Clin Med. 1994;7:123-131.

[25] Park HS, Jung KS. Enhanced neutrophil chemotactic activity after bronchial challenge in subjects with grain dust-induced asthma. Ann Allergy Asthma Immunol. 1998;80:257-262.

[26] Smith LJ, Shamsuddin M, Sporn PH, Denenberg M, Anderson J. Reduced superoxide dismutase in lung cells of patients with asthma. Free Radic Biol Med. 1997;22:1301-1307.

[27] Postępski J. Selected parameters of the oxidative-antioxidative balance in children with bronchial asthma exacerbations. Pol Merk Lek. 2001;65:385-388.
[28] Jakubczak B, Demkow U, Wąsik M. The activity of granulocytes in children with recurrent infections of respiratory tract. Pneumonol Alergol Pol. 2005;73:160-166.

[29] Kowalska M, Kowalska H, Zawadzka-Głos L, et al. Dysfunction of peripheral blood granulocyte oxidative metabolism in children with recurrent upper respiratory tract infection. Int $J$ Pediatr Otorhinolaryngol. 2003;67:365-371.

[30] Kjellman NI, Johansson SG, Roth A. Serum IgE levels in healthy children quantifield by a sandwich technique. Clin Allergy. 1976;6:51-56.

[31] Zarember KA, Godowski PJ. Tissue expression of human Toll-like receptors and differential regulation of Toll-like receptor mRNA in leukocytes in response to microbes, their products, and cytokines. J Immunol. 2002;15,168: 554-561.

[32] Akira S, Uematsu S, Takeuchi O. Pathogen recognition and innate immunity. Cell. 2006;24(124):783-801.

[33] Beutler B. TLR4: central component of the sole mammalian LPS sensor. Curr Opin Immunol. 2000;12:20-26.

[34] Prescott SL, Noakes P, Chow BW, et al. Presymptomatic differences in Toll-like receptor function in infants who have allergy. J Allergy Clin Immunol. 2008;122:391-399.

[35] Remer KA, Brcic M, Jungi TW. Toll-like receptor- 4 is involved in eliciting an LPS-induced oxidative burst in neutrophils. Immunol Lett. 2003;85(1):75-80.

[36] Sampson HA. Clinical manifestation in adverse food reaction. Pediatr Allergy Immunol. 1995;6:29-33.

[37] Parker LC, Moira KB, Dower SK, Sabroe I. Expression and roles of Toll-like receptors in the biology of human neutrophil. J Leukoc Biol. 2005;77:886-892.

[38] Roos D, van Bruggen R, Meischl C. Oxidative killing of microbes by neutrophils. Microb Infect. 2003;5:1307-1315.

[39] Calhoun WJ, Bush RK. Enhanced reactive oxygen species metabolism of airspace cells and airway inflammation follow antigen challenge in human asthma. J Allergy Clin Immunol. 1990;86:306-313.

[40] Kim JY, Lee KH, Lee BK, Ro JY. Peroxynitrite modulates release of inflammatory mediators from guinea pig lung mast cells activated by antigen-antibody reaction. Int Arch Allergy Immunol. 2005;137:104-114.

[41] Ghosh S, Janocha AJ, Aronica MA, et al. Nitrotyrosine proteome survey in asthma identifies oxidative mechanism of catalase inactivation. I Immunol. 2006;1(176):5587-5597.

[42] Lu Y, Wahl LM. Oxidative stress augments the production of matrix metalloproteinase-1, cyclooxygenase-2 and prostaglandin E2 through enhancement of NF-kappa B activity in lipopolysaccharide-activated human primary monocytes. J Immunol. 2005;15(175):5423-5429.

[43] Rollet-Labelle E, Grange MJ, Elbim C, Marquetty C, Gougerot-Pocidalo MA, Pasquier C. Hydroxyl radical as a potential intracellular mediator of polymorphonuclear neutrophil apoptosis. Free Radic Biol Med. 1998;1(24):573-572.

[44] Szlagatys-Sidorkiewicz A, Góra -Gebka M, Korzon M. Reactive oxygen species and antioxidative barrier in asthma. Pneumonol Alergol Pol. 2007;75:158-162.

[45] Fitzpatrick AM, Teague WG, Holguin F, Yeh M, Brown LA. Airway glutathione homeostasis is altered in children with severe asthma: evidence for oxidant stress. J Allergy Clin Immunol. 2009;123:146-152. 